\title{
Los derechos humanos laborales en el Derecho internacional
}

\author{
MIGUEL F. CANESSA MONTEJO*
}

En los últimos años, asistimos a una revaloración del Derecho internacional del trabajo, durante la que su reposicionamiento se ve fortalecido con los derechos humanos laborales -el espacio de intersección entre el Derecho internacional del trabajo y el Derecho internacional de los derechos humanos- - El presente estudio pretende abordar esa temática desde el horizonte del Derecho internacional. He dividido el análisis en cinco grandes partes. En el primer acápite se plantea un concepto para este selecto grupo de derechos laborales básicos, así como se postulan los argumentos que justifican su reconocimiento jurídico en los instrumentos internacionales de derechos humanos. En el segundo acápite se aborda la identificación de los derechos laborales con los derechos sociales, como una forma de desvalorizar su relevancia jurídica. En el tercer acápite se resaltan las singularidades de los derechos humanos laborales, lo que dificulta someterlos a la clásica división entre derechos civiles y derechos sociales. En el cuarto acápite se establecen las obligaciones internacionales que se desprenden de los derechos humanos laborales hacia los Estados. Asimismo, se hace un breve recorrido sobre los procedimientos internacionales de control y los más importantes pronunciamientos de protección de los derechos humanos laborales. Finalmente, en el último acápite se presenta el jus cogens laboral como pilar del Derecho internacional del trabajo.

I.

Con la Declaración Universal de Derechos Humanos y los pactos internacionales de 1966, se produce un cambio cualitativo en el Derecho internacional: un grupo de derechos laborales son incluidos dentro del selecto listado de derechos humanos. Esto se explica por qué desde el principio los derechos laborales formaron parte en la conformación de los derechos humanos dentro del Derecho internacional. La Constitución de la Organización Internacional del Trabajo (1919), la redacción de las primeras normas internacionales del trabajo — convenios y recomendaciones-, el establecimiento de los procedimientos de control de la OIT y la Declaración de Filadelfia (1944) tuvieron una gran influencia en la redacción de la Declaración Universal. 
Este selecto grupo de derechos laborales son la libertad de trabajo, la prohibición de la esclavitud y de la servidumbre, la prohibición del trabajo forzoso u obligatorio, el derecho al trabajo, la protección contra el desempleo, la protección contra el despido, la prohibición de la discriminación en materia de empleo y ocupación, la igualdad de remuneración por un trabajo de igual valor, la prohibición de la discriminación de personas con responsabilidades familiares, la seguridad e higiene en el trabajo, el derecho a condiciones justas, equitativas y satisfactorias del trabajo - la jornada máxima de trabajo, el descanso semanal remunerado, el descanso remunerado en feriado y las vacaciones periódicas pagadas-, el derecho a un remuneración mínima, el derecho a la promoción en el empleo, el derecho a la formación profesional, el derecho a la información y a la consulta en el seno de la empresa, el derecho a la información y a la consulta en los procedimientos de despido colectivo, el derecho a la tutela de los créditos en caso de insolvencia de sus empleadores, la libertad sindical, el derecho a la protección de los representantes de los trabajadores y facilidades para el ejercicio de sus funciones, la negociación colectiva, el derecho a la huelga, el derecho a la seguridad social — asistencia médica, prestaciones monetarias o seguros de desempleo, enfermedad, invalidez, viudez, vejez y otros casos; prestaciones por accidentes de trabajo y enfermedades profesionales; prestaciones de maternidad, etcétera-, y la protección especial a los menores de edad, a las mujeres trabajadoras, a los trabajadores migrantes y a los minusválidos.

Ante la disparidad de términos que se usan para identificar a este importante grupo de derechos laborales básicos recogidos en los instrumentos internacionales de derechos humanos, he seleccionado el término derechos humanos laborales como el más apropiado, en razón de que no se trata de una denominación nueva o reciente en el Derecho internacional, sino que su uso es continuo por las organizaciones internacionales y los organismos privados. A su vez, es un término que se emplea indistintamente en los idiomas como equivalentes (derechos humanos laborales en castellano; human labor rights en inglés; droits humains de travail en francés), lo cual facilita su comprensión y reduce eventuales confusiones. Asimismo, se debe resaltar que se trata de una expresión recogida por la jurisprudencia internacional para referirse precisamente a los derechos laborales señalados en los instrumentos internacionales de derechos humanos. Además, es un término funcional que permite incluir el listado completo de los derechos laborales básicos, sin rechazar que la técnica jurídica formule categorías, distingos o jerarquías dentro de sus componentes, por lo cual supera en flexibilidad a otros términos afines. Finalmente, es un término que expresa con claridad la titularidad universal de los derechos.

En un plano formal, los derechos humanos laborales se podrían definir como todos aquellos derechos en materia laboral recogidos en instrumentos internacionales de derechos humanos que reconocen 
universalmente como titular a la persona. Su fundamentación proporciona argumentos consistentes que justifican la existencia o reconocimiento de este grupo de derechos; en particular, afianzan su reconocimiento en los instrumentos internacionales a través de dos grandes argumentos.

El primero pone el acento en la existencia de necesidades básicas que padecen todos los seres humanos que forman parte del mundo del trabajo y que no son creadas por ellos mismos. Esas necesidades reclaman su satisfacción para evitar un daño o un perjuicio grave a las personas que puedan sufrirlo. La exigencia ética de la satisfacción está vinculada estrechamente con las condiciones indispensables que permiten al individuo actuar con autonomía y asegurar su supervivencia. Así, por medio de un debate democrático y público, se discute si este tipo de necesidades deben ser satisfechas; aquellas que reciban la aprobación por responder al interés o a un valor generalizable de sus miembros son reconocidas como derechos. Este primer argumento se puede denominar «fundamentación antropológica» de los derechos humanos laborales. Su ventaja teórica es que, al apoyarse sobre la teoría de las necesidades, en la que se coloca al «trabajo» como un punto neurálgico de su formulación, permite presentar de manera universal las consecuencias de la insatisfacción de las necesidades como un daño generalizado, con independencia del contexto social, cultural o económico en que se produce. Asimismo, la especificidad de las necesidades en el mundo del trabajo requiere de respuestas jurídicas precisas y particulares, lo que hace de los derechos humanos laborales un grupo cuyos sujetos titulares gozan de una mayor determinación.

Un segundo argumento reside en el valor intrínseco que poseen los seres humanos - la dignidad - , que nos ennoblece a la condición de personas -o sujetos de derechos-. Este reconocimiento del valor intrínseco de los seres humanos es resultado de formaciones socioculturales habitualizadas dentro del mundo intersubjetivo de las personas, en el que el significado de dignidad adquiere tal importancia que se institucionaliza en el colectivo social, y es en consecuencia aprehendido e internalizado. Esto explica que dicho valor fundamental sea incorporado al orden institucional para asegurar la centralidad del individuo por medio de los derechos básicos con independencia del escenario social, lo que sin duda incluye al mundo del trabajo. Este segundo argumento se puede denominar «fundamentación axiológica» de los derechos humanos laborales.

Ambas argumentaciones pasan la prueba de la validación del principio de universalización habermasiano, en tanto se encuentran formulados bajo un interés generalizable y no provocan rechazo legítimo en su aceptación por parte de los miembros de la comunidad. Esta validación refuerza en términos morales el consenso fáctico universal alcanzado por los Estados al consagrar los derechos laborales dentro de los instrumentos internacionales de derechos humanos. 
Apoyado sobre la plausibilidad de estas argumentaciones, se pueden introducir las justificaciones dentro del concepto de los derechos humanos laborales para reformular su contenido de este modo: los derechos humanos laborales son todos aquellos derechos en materia laboral consagrados en instrumentos internacionales de derechos humanos que reconocen universalmente como titular a la persona, respetan la dignidad humana y satisfacen las necesidades básicas en el mundo del trabajo.

II.

En el mundo jurídico, se suelen identificar los derechos laborales con los derechos sociales, y esto no debe interpretarse como un cuestionamiento a su inclusión dentro del listado de los derechos humanos. Para justificar esta afirmación se debe demostrar que no existe incompatibilidad entre las características de los derechos sociales y las de los humanos, lo que desvirtúa la opinión de que solo los derechos civiles y políticos califican para ser derechos humanos.

En primer lugar, el carácter prestacional (obligaciones de dar o hacer) atribuido a los derechos sociales también puede ser reconocido en la gran mayoría de los derechos civiles y políticos. Por ejemplo, el derecho al debido proceso o a la participación política requieren de la acción prestacional estatal para su ejercicio. Asimismo, el carácter prestacional no es un rasgo que se encuentre en todos los derechos sociales: ocurre con la libertad sindical o la huelga, que exigen la no interferencia del Estado para su ejercicio.

En segundo lugar, los derechos sociales no son derechos de igualdad, ni tampoco existe una superioridad axiológica entre los derechos de libertad y los derechos de igualdad. En realidad, los derechos sociales son derechos de libertad con raigambre igualitaria; su finalidad es satisfacer las condiciones previas a la acción humana para que las personas puedan ser realmente libres en su actuar. Esta lectura de los derechos sociales permite armonizar la igualdad y la libertad en un mismo plano jurídico, ante lo cual se rechaza cualquier visión jerárquica entre ellos.

En tercer lugar, el carácter absoluto de los derechos humanos es la excepción de la regla, pues son muy pocos los derechos humanos que gozan de tal característica: por ejemplo, la no privación arbitraria de la vida, la prohibición de la tortura, la presunción de inocencia. En general, los derechos humanos poseen limitaciones y restricciones que vienen establecidas por el propio ordenamiento. También es falso afirmar que los derechos civiles son los que limitan a los derechos sociales. Por ejemplo, los derechos laborales son límites a la libertad de empresa o a la libertad de contratación; el derecho a la salud puede ser una restricción a la libertad de circulación de las personas. 
En cuarto lugar, la universalidad de los derechos está fijada para el supuesto de las personas que se benefician de él, sin que esto signifique una restricción del acceso a la titularidad del derecho. Así, todos los miembros de la sociedad son titulares de un derecho social, aunque el ejercicio del derecho beneficie a las personas que requieran la satisfacción de la necesidad básica. Inclusive los derechos civiles y políticos se estructuran bajo esta forma jurídica: el ordenamiento exige a los titulares de los derechos gozar de la capacidad de obrar para poder ejercitarlos. Contamos con ejemplos como el derecho a contraer matrimonio, el derecho a celebrar contratos, el derecho al voto, etcétera. En cambio, el derecho a la educación o el derecho a la salud son de titularidad universal: todos los miembros de la sociedad gozan de ellos. En el caso de los derechos laborales, su titularidad no se condiciona a que los titulares gocen de la capacidad de obrar o a que sean ciudadanos: todas las personas son titulares de los derechos humanos laborales. El caso de los trabajadores migrantes supone un buen ejemplo, pues son titulares de estos derechos independientemente de su condición legal de residencia.

En quinto lugar, los derechos sociales tienen serias dificultades con relación a ser justiciables pero no por la ausencia de una sanción — porque suele ordenarse una indemnización si se verifica su violación-, sino por las lagunas que presentan sus garantías. La ausencia de adecuadas garantías provoca que sean justiciables. Los derechos sociales recogidos en los textos constitucionales cuentan con un nivel de aplicación aun cuando carecen de garantías: cualquier norma inferior que viole su contenido deberá ser suprimida del ordenamiento. Si el derecho social no existiese o fuese meramente programático, carecería de dicho atributo. Por ello los derechos sociales son subjetivos. Con el derecho al trabajo, por ejemplo, ocurre algo distinto: a pesar de su carácter controversial, los tribunales constitucionales han señalado la inconstitucionalidad de legislaciones por violar este derecho. En el caso del Derecho internacional, los derechos sociales son recogidos como progresivos; es decir, cada derecho posee un contenido esencial protegido por normas que imponen obligaciones mínimas para los Estados, y se permite un lapso para la aplicación plena y efectiva de las demás obligaciones. Finalmente, para el caso de los derechos laborales, resulta difícil plantear que no son justiciables cuando tienen una rama procesal propia con principios e instituciones que aseguran su cumplimiento.

En sexto lugar, se debe aceptar que la escasez es un limitante para el cumplimiento de los derechos - tanto civiles como sociales-. Sin embargo, es equivocado plantearlo como un fenómeno natural de las sociedades contemporáneas, cuya solución se resuelve al asegurar el incremento de la riqueza. Este razonamiento conduce a la suspensión de la aplicación de los derechos sociales mientras no se alcancen los niveles económicos necesarios para su cumplimiento. Este principio ha sido rechazado por los organismos internacionales de control. Los derechos sociales están protegidos por obligaciones mínimas no sujetas a la condición material 
de recursos existentes, y los Estados están subordinados a ellas. El verdadero debate sobre la escasez consiste en establecer un criterio que asegure la satisfacción de las necesidades más elementales de la población. No se trata de cuestionar la existencia de los derechos sociales, sino de discutir efectivamente cuál es el núcleo esencial de los derechos sociales y cuáles son los mecanismos que aseguran su disfrute.

En séptimo lugar, las Naciones Unidas han rechazado que los Pactos Internacionales de 1966 signifiquen poner en tela de juicio la unicidad de los derechos humanos. Si bien se elaboraron dos instrumentos internacionales distintos, se subrayó que los derechos humanos están constituidos de forma interrelacionada e interdependiente. Sobre ese postulado se constituyó la teoría de la indivisibilidad y la interdependencia de los derechos humanos. Dicha teoría plantea que los derechos humanos están conformados por un compacto grupo de derechos estrechamente interrelacionados, fundamentados en la dignidad humana, y que la elaboración de los dos pactos internacionales tiene por finalidad facilitar su cumplimiento. El respaldo a la teoría proviene de los pronunciamientos de los órganos de control de las Naciones Unidas. En realidad, la teoría acepta las diferencias entre los derechos pero resalta que por encima se ubica la propia unicidad de los derechos humanos.

Estas conclusiones rebaten los cuestionamientos que ponen en tela de juicio la ubicación de los derechos sociales dentro de la lista de derechos humanos.

III.

Si bien existe un tronco común de nacimiento entre los derechos laborales y los derechos sociales, la propia evolución jurídica ha ido perfilando diferencias que merecen resaltarse. La visión tradicional considera que el carácter prestacional es el rasgo definidor de los derechos sociales, pero esta postura entra en conflicto con la naturaleza de una serie de derechos laborales, tales como la libertad de trabajo o la libertad sindical, respecto de los cuales la obligación principal es la no interferencia del Estado o de terceros en su ejercicio. Desde esa visión, se trataría de derechos civiles en lugar de derechos sociales. Este tipo de dificultades reside en que se pretende someter a los derechos laborales a los rígidos parámetros de los derechos de igualdad, en contraposición con los derechos de libertad. Los derechos sociales son derechos de libertad con raigambre igualitaria; superan la falsa contraposición entre derechos de libertad y derechos de igualdad. Los derechos laborales gozan de una naturaleza «mixta» o «doble» que explica la existencia de derechos con expectativas negativas o positivas, panorama en el que a unos les corresponden prohibiciones de lesión y a otros, obligaciones de prestación.

La particularidad de los derechos laborales reside en que su objetivo es proteger la libertad en el mundo del trabajo. El contrato de trabajo y 
su cumplimiento se constituyen sobre la restricción del ejercicio de la libertad del trabajador durante la vigencia del contrato. El trabajador acepta someter su libertad dentro de la jornada laboral porque esto es lo que le permite al empleador aprovechar el uso de la fuerza de trabajo. Se trata de la subordinación del trabajador. Y si bien este acepta libremente restringir su libertad, muchas veces la situación de carencia en que vive condiciona la autonomía de su voluntad, por lo que el contrato de trabajo puede esconder algún menoscabo sobre él. Así, los derechos laborales se constituyen como respuesta jurídica a esa libertad mermada.

La libertad del trabajador requiere ser protegida no solo por su propia debilidad sino también porque el empresario representa un centro de poder en la relación laboral. Este centro de poder requiere un control en los mismos términos que ocurre con los otros poderes de la sociedad, porque ambos son un eventual peligro para la libertad. Los derechos laborales se insertan dentro de la categoría de los derechos humanos con la peculiaridad de estar ubicados, a su vez, dentro de una relación entre particulares —empleadores y trabajadores - en la que el Estado cumple un importante rol tutelar. El equilibrio del derecho laboral consiste en proteger la libertad de los trabajadores y conseguir la estabilidad del sistema productivo.

Se pueden identificar tres singularidades de los derechos humanos laborales. En primer lugar, tienen como titular a la persona humana, lo cual supone una extensión de su ámbito de protección en comparación con algunos ordenamientos nacionales. Así, los trabajadores nacionales y extranjeros, los trabajadores subordinados, los trabajadores semiautónomos, los trabajadores autónomos e inclusive los propios empleadores son titulares de derechos humanos laborales. Por supuesto, algunos derechos formulan restricciones o exclusiones en la titularidad: esto responde a la propia naturaleza del derecho. En segundo lugar, las normas que protegen los derechos humanos laborales imponen obligaciones internacionales a los Estados, y estos están sujetos a los procedimientos de control estipulados en los instrumentos internacionales. En tercer lugar, los derechos humanos laborales son recogidos en términos de principios; fijan un contenido esencial y permiten que las legislaciones nacionales los adecuen a su ámbito normativo.

IV.

Las transformaciones que provoca la globalización en el mundo del trabajo hacen insuficientes los esfuerzos desde los derechos nacionales de trabajo para abordar un fenómeno que trasciende sus fronteras. De igual modo, los esfuerzos desde la OIT son meritorios pero todavía incompletos, ya que sus miembros son renuentes a adquirir nuevos compromisos internacionales. 
Frente a este panorama, los derechos humanos laborales están en mejores condiciones para enfrentar los retos de la globalización. En primer lugar, estos son una herramienta jurídica esencial en el Derecho internacional: aseguran el respeto de la dignidad humana y la satisfacción de las necesidades básicas en el mundo del trabajo. En segundo lugar, tienen por titular a la persona humana en sus diversas modalidades de trabajador. En tercer lugar, imponen obligaciones a los Estados, y estas obligaciones aseguran un piso mínimo internacional para cualquier relación laboral. Así, cualquier relación de trabajo en el mundo que merezca llamarse «digna» supone su respeto. Lo sustancial es que los derechos humanos laborales son una normativa internacional existente -no «por crear»— con un conjunto de procedimientos de control a los que se encuentran vinculados los Estados y con pronunciamientos internacionales que amparan su protección. Así, la exigencia por controlar la globalización económica desde un espacio supranacional en realidad ya está materializado con los derechos humanos laborales. Sin embargo, esto no impide que se efectúen reformas o agregados que mejoren la regulación internacional.

La naturaleza jurídica y las obligaciones impuestas por los instrumentos internacionales de derechos humanos establecen el marco normativo internacional de los derechos humanos laborales. En el caso de los instrumentos internacionales abiertos a su ratificación o adhesión para los Estados, como los pactos internacionales de 1966 o la Convención Americana sobre Derechos Humanos, o el Convenio Europeo de los Derechos Humanos, no cabe duda de que el carácter vinculante surge con el depósito de la ratificación o adhesión del Estado. En cambio, el carácter vinculante de la Declaración Universal de Derechos Humanos o de la Declaración Americana sobre los Derechos y Deberes del Hombre es más discutible.

La Carta de las Naciones Unidas establece entre sus fines la promoción del respeto universal de los derechos humanos y las libertades fundamentales de las personas, sin hacer distinción por motivo de raza, sexo, idioma o religión. Sin embargo, no establece un listado de los derechos humanos y las libertades fundamentales recogidos por la Carta; al margen de ello, en el caso de los derechos laborales, existe una referencia a promover el trabajo permanente para todos (artículo 55, inciso a) y, en términos generales, a la prohibición de la discriminación (artículo 55, inciso c). La ausencia de un listado de derechos humanos y libertades fundamentales se resuelve si se adopta una lectura conjunta entre la Carta de las Naciones Unidas y la Declaración Universal de Derechos Humanos (DUDH), donde esta cumple el rol de complementar la Carta. Esta lectura conjunta significaría que la Declaración Universal gozaría de un carácter vinculante para los Estados miembros del organismo internacional, en razón de que la obligatoriedad de la Carta hacia la Declaración se extendería. Sin embargo, es una interpretación que no goza del respaldo de la doctrina jurídica en su conjunto. 
Enfrente de esta interpretación formal de la Declaración Universal que rechaza su carácter vinculante y lo reduce a una exigencia moral de respeto para los Estados, existe una serie de argumentos que respaldan la obligatoriedad de la DUDH. En primer lugar, los pronunciamientos de la Corte Internacional de Justicia en los que se establece la existencia de principios fundamentales contenidos en la Declaración. En segundo lugar, la práctica institucional de las Naciones Unidas de someter las comunicaciones sobre denuncias de violaciones de derechos humanos a los mecanismos extraconvencionales, con independencia de que los Estados hayan ratificado alguno de los Pactos Internacionales de 1966, ante lo cual la lectura conjunta de la Carta y la Declaración Universal justifica esta práctica. En tercer lugar, una significativa cantidad de Estados declaran que la DUDH tiene un carácter obligatorio e incorporan los derechos humanos dentro de sus constituciones nacionales, con lo que manifiestan una opinio juris sobre la materia. En mi opinión, estos argumentos llevarían a concluir que los derechos laborales recogidos en la DUDH son exigibles internacionalmente a los Estados.

Aunque la Declaración Americana sobre los Derechos y Deberes del Hombre no es un tratado internacional sujeto a ratificación de los Estados, sí constituye una fuente de obligaciones para los Estados miembros de la OEA en materia de derechos humanos, por su estrecho vínculo con la Carta de la OEA y con la práctica reiterada de los Estados americanos. Así lo interpretan la Corte y la Comisión Interamericana de Derechos Humanos. Esto significaría que los derechos humanos laborales recogidos en la Declaración Americana son obligatorios para los Estados del hemisferio.

En el sistema universal especializado de derechos humanos laborales, la Organización Internacional del Trabajo cumple un rol central. El carácter vinculante de la Constitución de la OIT (1919) incluye su Preámbulo y Principios Generales secciones en las que se encuentran recogidos los derechos humanos laborales. Esta interpretación se sustenta en los innumerables comentarios de los órganos de control del organismo internacional. Igualmente, la Declaración de Filadelfia (1944), que modificó los Principios Generales de la Constitución de la OIT y que fue agregada a esta, tiene carácter vinculante para los Estados miembros de la OIT. Finalmente, la Declaración de la OIT (1998) no crea obligaciones nuevas para los Estados miembros, sino que se trata de un instrumento promocional que resalta su compromiso de respetar, promover y hacer realidad los principios y derechos fundamentales en el trabajo, recogidos en la Constitución de la OIT y la Declaración de Filadelfia.

Se debería interpretar la Declaración de la OIT como el esfuerzo institucional de promover determinado grupo de derechos laborales, pero sin desmerecer o redefinir la importancia del resto de derechos humanos laborales. En primer lugar, la Declaración de la OIT no modifica su Constitución. En segundo lugar, la Declaración de la OIT es un instrumento internacional promocional y no estrictamente normativo, por lo 
que tampoco puede considerarse como un instrumento interpretativo de la Constitución de la OIT. En tercer lugar, el objetivo de la Declaración de 1998 es lograr que los Estados miembros ratifiquen los convenios fundamentales de la OIT para asegurar su aplicación dentro de su jurisdicción y para estar sometidos a los procedimientos de control del organismo internacional.

Los instrumentos internacionales de derechos humanos imponen ciertas obligaciones a los Estados: en primer lugar, la obligación de respetar los derechos y las libertades recogidos en el instrumento internacional; en segundo lugar, la obligación de proteger los derechos y libertades recogidos en el instrumento internacional; en tercer lugar, la obligación de no discriminar en la titularidad el goce y el ejercicio de los derechos y libertades recogidos en el instrumento internacional; en cuarto lugar, la obligación de adoptar medidas para hacer efectivos los derechos y las libertades recogidos en el instrumento internacional.

Las medidas, por su lado, también están sujetas a una serie de lineamientos. Su adopción debe producirse dentro de un plazo razonable desde la entrada en vigencia el instrumento internacional en el ordenamiento interno. Deben derogar, modificar o reformar la legislación para hacerla acorde a los derechos y las libertades recogidos en el instrumento internacional. Deben aprobar la legislación que asegure el respeto, la protección y el cumplimiento de los derechos y de las libertades recogidos en el instrumento internacional. Deben suprimir las prácticas que entrañen una violación de los derechos y las libertades recogidos en el instrumento internacional. Por último, están obligadas a ofrecer recursos jurídicos internos efectivos, que aseguren la protección de los derechos y las libertades recogidos en el instrumento internacional.

En el caso específico de los derechos humanos laborales del Pacto Internacional de Derechos Económicos, Sociales y Culturales (PIDESC), se establece la obligación de satisfacer los niveles mínimos esenciales de cada uno de ellos. Asimismo, la igualdad de remuneración por trabajo de igual valor, la libertad sindical, el derecho de huelga y la protección del menor de edad (en materia laboral) gozan de aplicación inmediata.

En el caso específico de los derechos humanos laborales de la Carta Africana de los Derechos Humanos y de los Pueblos (CAFDH), se establece la obligación de promover y asegurar, mediante la enseñanza, la educación y la difusión, el respeto a los derechos y las libertades de la Carta; la aplicación de medidas para asegurar que se comprendan estos derechos y libertades; y sus correspondientes obligaciones y deberes.

Este conjunto de obligaciones cubre las relaciones laborales tanto en el sector público como en el privado. Asimismo, su protección alcanza tanto los actos cometidos por agentes del Estado como por personas particulares o entidades privadas. 
Bajo circunstancia alguna pueden ser suspendidas las obligaciones y las garantías de la prohibición de la esclavitud y la servidumbre, ni de la prohibición de cualquier tipo de discriminación en materia laboral, o formularse reservas al respecto.

Los instrumentos internacionales de derechos humanos han establecido distintos tipos de procedimientos y han constituido una variedad de órganos de control que aseguran la protección internacional de los derechos humanos laborales.

En el sistema universal de los derechos humanos, los principales órganos de las Naciones Unidas cumplen un relevante rol de protección de los derechos humanos laborales. La Asamblea General de las Naciones Unidas ha adoptado resoluciones para la creación de procedimientos de control, así como para condenar graves violaciones de derechos humanos laborales, como en el caso de Myanmar (Birmania). El Consejo de Seguridad se ha pronunciado por medio de sus resoluciones sobre graves violaciones de los derechos humanos laborales; por ejemplo, su Resolución 310 de 1972 condena a Sudáfrica por las medidas represivas que caían sobre los trabajadores africanos en Namibia. El Consejo Económico y Social (ECOSOC) ha establecido los procedimientos no convencionales de protección de los derechos humanos (1235 y 1503) y ha conformado diversos órganos de control, como el Consejo de Derechos Humanos — antes llamado Comisión de Derechos Humanos-, y otros órganos subsidiarios, tales como el Comité de Derechos Económicos, Sociales y Culturales (CDESC). La Corte Internacional de Justicia cumple una valiosa labor por medio de sus competencias contenciosa y consultiva, y se pronuncia sobre temas directamente vinculados con los derechos humanos. La Secretaría General de las Naciones Unidas, por intermedio de sus órganos, desarrolla importantes actividades en el área de los derechos humanos e impulsa políticas institucionales, como el Pacto Mundial (Global Compact), para la promoción de principios sociales y medioambientales que incluyen los derechos humanos y las relaciones laborales.

Los procedimientos convencionales del sistema universal de derechos humanos están divididos en los sistemas de reportes, la presentación de quejas y las denuncias ante los tribunales internacionales.

Los derechos humanos laborales están cubiertos por un sistema de reportes: los dos pactos internacionales de 1966; la Convención sobre la Eliminación de la Discriminación Racial; el Convenio de la Eliminación de Todas las Formas de Discriminación contra la Mujer; la Convención de los Derechos del Niño, y la Convención Internacional sobre la Protección de los Derechos de los Trabajadores Migratorios y de sus Familiares. Los comités —órganos de control de los sistemas de reportes- han alcanzado notables éxitos al conseguir que los Estados parte cumplan con las obligaciones impuestas por los instrumentos internacionales de

LOS DERECHOS

HUMANOS

laborales en

EL DERECHO

INTERNACIONAL 
derechos humanos. En el caso de los derechos humanos laborales, se pueden mencionar como ejemplos los pronunciamientos del Comité de Derechos Humanos sobre la falta de una ley que prohíba la discriminación en el empleo (Venezuela) o la exigencia de una legislación que garantice a los trabajadores una jubilación mínima adecuada (Argentina). Sus Observaciones Generales sobre Discriminación ( $\left.\mathrm{N}^{\circ} 18\right)$ e Igualdad de Derechos entre Hombres y Mujeres $\left(\mathrm{N}^{\circ} 28\right)$ abordan temas laborales. Igualmente, el Comité de Derechos Económicos, Sociales y Culturales se ha pronunciado sobre violaciones de derechos humanos laborales. Hay que destacar su reciente Observación General sobre el Derecho al Trabajo ( $\left.\mathrm{N}^{\circ} 18\right)$.

Los derechos humanos laborales protegidos por la presentación de quejas se ubican en el Pacto Internacional de Derechos Civiles y Políticos (PIDCP) y en su Primer Protocolo Facultativo, en la Convención Internacional sobre la Eliminación de Todas las Formas de Discriminación Racial, en el Protocolo Facultativo de la Convención de la Eliminación de Todas las Formas de Discriminación contra la Mujer, y en la Convención Internacional sobre la Protección de los Derechos de los Trabajadores Migratorios y de sus Familiares.

En este tipo de procedimientos, se pueden resaltar importantes pronunciamientos para los derechos humanos laborales. El Comité de Derechos Humanos ha señalado que el hostigamiento de los dirigentes sindicales - como el arresto, la detención sin juicio, la tortura y el tratamiento cruel, inhumano o degradante- constituye una violación de la libertad sindical (caso Saldías vs. Uruguay). El Comité para la Eliminación de la Discriminación Racial ha establecido que no es discriminatorio el sistema de cupos de profesionales extranjeros, si todos están sometidos al mismo sistema (caso BMS vs. Australia).

Son pocas las denuncias ante tribunales internacionales por la violación de algún derecho laboral. Sin embargo, no se debe desvalorizar su impacto para el Derecho internacional de trabajo.

La Corte Internacional de Justicia, en sus dos competencias - contenciosa y consultiva-, ha interpretado los derechos humanos recogidos en los instrumentos internacionales y ha definido las obligaciones de los Estados respecto de los derechos humanos. En su competencia contenciosa resalta el caso Barcelona Traction, para el que establece la diferencia entre obligaciones de un Estado respecto de los otros y obligaciones de un Estado respecto de la comunidad internacional en su conjunto: reconoce dentro de estas últimas las obligaciones erga omnes, e identifica la prohibición de la esclavitud y la discriminación racial como principios y reglas relativos a los derechos fundamentales de la persona. En su competencia consultiva, destaca su Opinión Consultiva sobre las Consecuencias Legales de la Construcción del Muro en el Territorio de la Palestina Ocupada, en la que señala que la construcción del muro implica la violación de una serie de derechos humanos, y destaca entre 
uno de ellos el derecho al trabajo. La Corte Penal Internacional no se ha pronunciado todavía sobre caso alguno, pero conforme a su estatuto es competente en el caso en que una persona natural viole la prohibición de la esclavitud, por ser considerado un crimen de lesa humanidad.

Los procedimientos extraconvencionales del sistema universal de derechos humanos están constituidos por los procedimientos públicos 1235 y por el procedimiento confidencial 1503. Ambos se ventilan ante el Consejo de los Derechos Humanos por la presentación de quejas individuales, a partir de las cuales se alega la violación de algún derecho humano. Los procedimientos públicos 1235 se dividen en geográficos y temáticos. Tanto en los procedimientos geográficos como en los temáticos se han ventilado quejas por violaciones de derechos humanos laborales, especialmente en países donde la actividad sindical es perseguida por los Estados. En cambio, el procedimiento confidencial 1503 ha tenido un escaso rol para la protección de los derechos humanos laborales.

En el sistema interamericano de derechos humanos, existen tres procedimientos de control: el sistema de reportes, el sistema de peticiones y los casos contenciosos ante la Corte Interamericana. A esto debería agregarse la competencia consultiva que cumple la Corte.

Los derechos humanos laborales están sujetos a tres sistemas de reportes dentro del sistema interamericano; en primer lugar, sobre los derechos consagrados en la Convención Americana de Derechos Humanos; en segundo lugar, sobre los derechos económicos, sociales y culturales contenidos en la Carta de la OEA; en tercer lugar, sobre los derechos consagrados en el Protocolo de San Salvador. La evaluación de los reportes es competencia de la Comisión Interamericana de Derechos Humanos (en adelante, la Comisión), que elabora sus informes anuales y especiales en función de la información recopilada.

En los informes anuales de la Comisión se encuentran publicados sus comentarios y recomendaciones sobre las diversas peticiones que le han sido sometidas. En cuanto a los derechos humanos laborales, al inicio de sus labores los casos se concentraron en la persecución o el asesinato de dirigentes sindicales. Posteriormente, con la consolidación de los regímenes democráticos en el hemisferio, este tipo de casos disminuyó y dio paso a peticiones por despidos antisindicales, incumplimiento de sentencias judiciales en favor de trabajadores o jubilados, el reconocimiento legal de organizaciones sindicales, entre otros. Desde 1996, los informes anuales de la Comisión incluyen una sección que analiza la situación de los trabajadores migrantes y sus familiares en el hemisferio. Sus estudios anuales revelan la vulnerabilidad de este grupo humano.

En sus informes especiales, por otro lado, la Comisión se pronuncia sobre violaciones a los derechos humanos laborales y retrata la situación jurídica entre los países estudiados. Sobre trabajo infantil, por ejemplo, se mencionan pésimas condiciones laborales y el preocupante incremento de

LOS DERECHOS HUMANOS laborales en EL DERECHO INTERNACIONAL 
menores que laboran. Asimismo, señala que es insuficiente una legislación que prohíba el trabajo infantil si es que no viene acompañada de una protección real en favor de los menores. Acerca de trabajo de las mujeres, se resaltan los abusos que sufren en sus empleos y la discriminación salarial frente a hombres. Igualmente, las poblaciones indígenas están sometidas a condiciones de explotación, especialmente en actividades agrícolas. La Comisión ha sido firme en sostener que el derecho al trabajo es un derecho humano que cubre una serie de derechos laborales que los Estados están obligados a respetar y garantizar. Ante el tema de los salarios, llama la atención sobre el incremento de las desigualdades salariales dentro de las economías nacionales y regionales. De igual modo, resalta tanto el incumplimiento del pago de los salarios mínimos nacionales como que sus montos no cubran el costo de la canasta básica familiar. La Comisión se ha pronunciado sobre las reiteradas violaciones a la libertad sindical que se producen en el hemisferio e inclusive sobre la contradicción entre las normas internas y la regulación internacional.

Los derechos humanos laborales están sujetos a tres procedimientos de examen de peticiones en el sistema interamericano. En primer lugar, se encuentran las peticiones dirigidas por la violación de algún derecho de la Declaración Americana. En segundo lugar, están las peticiones dirigidas por la violación de algún derecho de la Convención Americana. En tercer lugar, se hallan las peticiones dirigidas por la violación de la libertad sindical o el derecho a la educación recogido en el Protocolo de San Salvador. La Comisión es el órgano competente para recibir y examinar peticiones. Sus conclusiones y recomendaciones carecen de fuerza vinculante para los Estados, pero la Corte Interamericana (en adelante, la Corte) ha señalado que los Estados tienen la obligación de realizar sus mejores esfuerzos para aplicar las recomendaciones de la Comisión, en virtud del principio de buena fe.

Los casos contenciosos ante la Corte Interamericana solo pueden ser sometidos por la Comisión y los Estados parte de la Convención Americana que hayan reconocido la jurisdicción de la Corte. Se han presentado importantes casos contenciosos ante la Corte sobre violaciones de derechos humanos laborales. Al igual que con la Comisión, los primeros casos contenciosos consistían principalmente en asesinatos o desapariciones de dirigentes y activistas sindicales (caso Caballero Delgado y Santana); sin embargo, el tipo de casos contenciosos laborales se amplía con el caso Baena Ricardo y otros, en el que la Corte se pronuncia por la violación a la libertad sindical que sufren 270 trabajadores estatales despedidos en Panamá. En su sentencia sobre las excepciones preliminares, la Corte Interamericana establece que no existe duplicidad de procedimientos cuando los trabajadores alegan una violación ante los órganos de control de la OIT y simultánea o posteriormente ante el sistema interamericano, porque los fundamentos legales son distintos y, especialmente, porque las recomendaciones del órgano de control de la OIT no pueden equipararse con las sentencias de un tribunal internacional. 
Respecto de la sentencia sobre la cuestión de fondo, la Corte señala que las garantías judiciales establecidas en la Convención Americana son exigibles tanto en los procedimientos administrativos de carácter laboral como en los procesos judiciales laborales. Asimismo, adopta un concepto de libertad sindical que incluye su aspecto positivo - la formación o afiliación a una organización sindical — y su aspecto negativo — la no afiliación o la desafiliación a una organización sindical—. Al considerar que se trata de despidos antisindicales, la Corte ordena la reposición de los 270 trabajadores, el pago de los salarios caídos y el pago de una indemnización por concepto de reparaciones. Con ello la Corte se inclina por una reparación del daño mediante el principio restitutio in integrum, con el cual busca el restablecimiento de la situación jurídica antes de producirse la violación, siempre que esto sea posible. Este criterio se ha mantenido para posteriores casos contenciosos laborales en los que la Corte se ha pronunciado en favor de los trabajadores (caso Acevedo Jaramillo y otros). En el caso Cinco Pensionistas, la Corte estableció que el derecho a la pensión de jubilación es un derecho adquirido, por lo que debe incorporarse al patrimonio del jubilado.

Las opiniones consultivas de la Corte Interamericana han sido fundamentales para la interpretación y el alcance de los derechos humanos laborales en el hemisferio. En la Opinión Consultiva sobre la Colegiación Obligatoria de los Periodistas, señala que las colegiaciones obligatorias en general no afectan la libertad de trabajo, pero en el caso de los periodistas supondrían impedir el acceso de cualquier persona al uso de los medios de comunicación social. En la Opinión Consultiva sobre la Condición Jurídica y Derechos de los Migrantes Indocumentados, la Corte sostiene que la no discriminación, junto con la igualdad ante la ley y la igual protección de la ley en favor de todas las personas, son elementos constitutivos de un principio básico y general de los derechos humanos. Apoya su afirmación en que el principio de no discriminación está recogido en la totalidad de los instrumentos internacionales sobre la materia. La Corte concluye que el principio de igualdad ante la ley, igual protección ante la ley y no discriminación pertenecen al jus cogens. Asimismo, utiliza el término «derechos humanos laborales» para referirse a los derechos laborales que le son inherentes a la persona por su condición de trabajador. Finalmente, subraya que la calidad migratoria de una persona no puede constituir, de manera alguna, una justificación para privarla del goce y ejercicio de sus derechos humanos, entre ellos los de carácter laboral.

Dentro del sistema europeo de derechos humanos, existen cuatro procedimientos de control: el sistema de reportes, las reclamaciones colectivas, las denuncias individuales y las denuncias interestatales ante la Corte Europea.

A su vez, los derechos humanos laborales están protegidos en tres sistemas de reportes: en primer lugar, en los derechos recogidos en 
el Convenio Europeo de Derechos Humanos; en segundo lugar, en los derechos económicos recogidos en la Carta de Turín; por último, en los derechos recogidos en la Carta de Estrasburgo. En el sistema de reportes del Convenio Europeo no se ha establecido un órgano de control responsable para revisar los informes o reportes, lo cual constituye una de las razones de su poco uso. En cambio, el Comité Europeo de Derechos Sociales (ECSR por sus siglas en inglés) es el órgano responsable para los otros dos sistemas de reportes. Sus informes y comentarios son trasmitidos a los Estados y al Comité de Ministros, y este último puede adoptar recomendaciones hacia los Estados en los casos de violaciones. La debilidad del sistema de reportes europeos reside en que no establece tipo de sanción alguna para los Estados que incumplan las recomendaciones del Comité de Ministros.

En sus conclusiones sobre los reportes de los Estados, el ECSR ha abordado una gran variedad de derechos humanos laborales. Para el caso del derecho al trabajo, el comité sostiene que este derecho incluye tres principios: la prohibición de todas las formas de discriminación en el empleo, la prohibición del trabajo forzoso u obligatorio y la prohibición de cualquier práctica que pueda interferir en el derecho del trabajador a ganarse la vida mediante un empleo libremente elegido. Asimismo, apunta que el derecho a una remuneración mínima debe asegurar un estándar decente de vida y que bajo circunstancia alguna puede estar debajo de la línea de pobreza del país. Respecto de la libertad sindical, afirma que este derecho garantiza a los trabajadores y empleadores a organizarse, y establece una amplia noción de trabajador. Así, el ECSR incluye como titulares de la libertad sindical a los trabajadores semiautónomos y autónomos. Igualmente, señala que la noción de libertad sindical incluye su aspecto negativo, es decir, el derecho a no afiliarse o a desafiliarse de una organización sindical, por lo que declara como prácticas contrarias al instrumento internacional el closed shop o union security (modalidades de cláusulas sindicales).

Las reclamaciones colectivas son quejas presentadas por la aplicación insatisfactoria de un derecho recogido en las cartas de Turín o Estrasburgo. Se requiere el consentimiento del Estado denunciado, y la queja se tramita ante el ECSR. Al igual que en el sistema de reportes, no se establecen sanciones por el incumplimiento de las recomendaciones. Las reclamaciones colectivas presentadas han abordado diferentes derechos humanos laborales: la prohibición del trabajo infantil, la libertad de trabajo, la prohibición del trabajo forzoso, la discriminación en el empleo, el descanso semanal remunerado, la seguridad e higiene en el trabajo, la libertad sindical y la negociación colectiva, entre otros.

Las demandas individuales ante la Corte Europea de Derechos Humanos (ECHR) han significado un importante aporte del sistema europeo a la protección de los derechos humanos, al otorgar el derecho al acceso al tribunal internacional a cualquier persona física, organización 
no gubernamental o grupo de particulares que se considere víctima de una violación de los derechos reconocidos en el Convenio Europeo de Derechos Humanos (en adelante, $\mathrm{CEDH}$ ) o en sus protocolos. La sentencia que pone fin al proceso tiene carácter declarativo y es obligatorio para los Estados. Asimismo, la Corte Europea adopta el principio restitutio in integrum como mecanismo de reparación siempre que la legislación interna del Estado lo permita, conforme lo dispone el CEDH.

En la competencia contenciosa de la Corte Europea, se ha pronunciado en multitud de casos que abordan los derechos humanos laborales. Ha señalado que el trabajo de las personas detenidas por vagancia (caso De Wilde y otros; caso Droogenbroeck) y el trabajo de asesoría jurídica gratuita establecida por ley (caso Van der Mussele) no son forzosos u obligatorios. En el caso de la vagancia, la Corte Europea sostiene que el Convenio Europeo de Derechos Humanos permite el trabajo penitenciario siempre que no rebase los límites de la «normalidad» y en tanto se busque la rehabilitación de los presos. En el caso de la asesoría jurídica gratuita, la Corte Europea entiende que este tipo de labores se ubica dentro del ámbito del trabajo o servicio de las obligaciones cívicas normales señalado en el CEDH.

Sus controversiales sentencias sobre libertad sindical señalan que el derecho a consulta de las organizaciones sindicales (caso Sindicato Nacional de Policía Belga), el derecho a una negociación colectiva obligatoria (caso Sindicato de Conductores de Locomotoras Suecos; caso Wilson y otros), el derecho al beneficio de la retroactividad o el aumento del salario resultante de un convenio colectivo (caso Schmidt y Dahlström) no constituyen elementos indispensables de la libertad sindical. Asimismo, señala que la obligación de afiliarse a una asociación de derecho público (el Colegio de Médicos) no es una violación a la libertad sindical (caso Le Compte y otros; caso Albert y Le Compte). En el caso Young y otros, la Corte Europea rechaza el argumento de que el derecho a la libertad sindical en su aspecto negativo no ha sido expresamente recogido en el CEDH. Avanza en este razonamiento con el caso Singurjónsson, en el que establece que existe un consenso entre una gran mayoría de los Estados parte para salvaguardar el aspecto negativo de la libertad de asociación, por lo que se debe considerar que el artículo 11 del CEDH engloba un derecho de asociación negativo. La Corte Europea no encuentra que establecer restricciones al ejercicio de la libertad de asociación de los miembros de las fuerzas armadas signifique una violación a la libertad sindical (caso Rekvenyi). Ha subrayado que permitir a los empleadores a recurrir a incentivos económicos para inducir a los trabajadores a renunciar a sus importantes derechos sindicales significa que el Estado incumple con sus obligaciones positivas — es decir, asegurar el disfrute de los derechos-, lo que equivale a una violación de la libertad sindical (caso Wilson y otros). 
En cuanto a la prohibición a la discriminación en las relaciones laborales, los casos alemanes que prohíben el ingreso a la administración pública de personas que son miembros o que prohíben participar en partidos anticonstitucionales fueron los más resaltantes. En los casos Kosiek y Glasenapp, la Corte Europea afirma que el CEDH no regula el derecho al acceso a la administración pública, pero ello no significa excluir a los funcionarios públicos de la aplicación del Convenio. Asimismo, la exigencia de las normas alemanas de «lealtad política» a su Constitución como requisito de acceso al puesto de funcionario público no es violatorio del CEDH. Sin embargo, la Corte Europea matiza su criterio en el caso Vogt, al afirmar que el despido de una funcionaria motivado en la exigencia de la «lealtad política» es una sanción severa y violatoria del CEDH. En el caso Gaygusuz, afirma que un tratamiento es discriminatorio si no parte de una justificación objetiva y razonable, especialmente en el caso de la nacionalidad de una persona. En los casos Van Raalte y Willis, la Corte Europea afirma que no cabe una diferenciación basada en el sexo en el trato respecto de personas ubicadas en situaciones análogas.

Las demandas interestatales ante la Corte Europea de Derechos Humanos por la violación de algún derecho recogido en el CEDH o en sus protocolos no han tenido relevancia alguna para los derechos humanos laborales.

El sistema africano de derechos humanos cuenta con tres tipos de procedimientos de control: el sistema de reportes, las denuncias interestatales y las comunicaciones o denuncias individuales. La Comisión Africana de los Derechos Humanos es el órgano responsable para los tres procedimientos. La ausencia en el sistema de reportes africanos de algún tipo de sanción para los Estados parte que no remiten la información a la cual se encuentran obligados por la ratificación de la carta ha llevado a que el sistema sea débil y su incumplimiento generalizado. Asimismo, el sistema de reportes carece de un adecuado seguimiento para las observaciones presentadas por la comisión, especialmente en los casos de incumplimientos graves sobre la aplicación de las normas de la carta dentro de los Estados. En cuanto a las denuncias interestatales, este procedimiento no ha sido utilizado por los Estados. Respecto de las comunicaciones o denuncias individuales, estas carecen de una normativa precisa para el seguimiento de las recomendaciones señaladas por la comisión. La Conferencia de Jefes de Estado y de Gobierno es renuente a condenar o sancionar a un Estado que viola la Carta Africana. El hecho de que solo por autorización de la conferencia se puedan hacer públicas las decisiones de la comisión debilita notoriamente el procedimiento de control.

Los derechos humanos laborales recogidos en la OIT son protegidos bajo tres tipos de procedimientos: el procedimiento de control regular, el procedimiento de control general y los procedimientos especiales de control. 
El procedimiento de control regular consiste en la evaluación de memorias de los Estados. Existen cuatro clases: las memorias sobre los convenios ratificados, las memorias sobre los convenios no ratificados y las recomendaciones, las memorias especiales sobre la Declaración de la OIT, y las informaciones sobre la sumisión a las autoridades competentes. Expertos Consejeros es el órgano responsable para las memorias especiales de la Declaración de la OIT, mientras que la Comisión de Expertos y la Comisión de Aplicación son los órganos responsables para las otras memorias e informaciones. La Comisión de Expertos se pronuncia sobre el cumplimiento de las normas internacionales del trabajo elaboradas en el seno de la OIT, que cubren todos los derechos humanos laborales, y se apoyan muchas veces en los pronunciamientos de los órganos de control de los instrumentos internacionales de derechos humanos. Sus pronunciamientos suelen analizar la legislación nacional, la jurisprudencia y las prácticas que se desarrollan en el país, especialmente si están en armonía con los principios establecidos en las normas internacionales del trabajo.

El procedimiento de control general se realiza por medio de dos mecanismos: las reclamaciones y las quejas. Las reclamaciones son presentadas por las organizaciones de empleadores y de trabajadores contra un Estado que no ha adoptado las medidas necesarias para el cumplimiento satisfactorio del convenio ratificado. Un comité tripartito es el órgano responsable de tramitar la reclamación. Las quejas son presentadas por un Estado miembro, por el Consejo de Administración o por un delegado asistente a la Conferencia Internacional del Trabajo contra un Estado que no ha adoptado las medidas necesarias para el cumplimiento satisfactorio del convenio ratificado. Una Comisión de Encuesta es responsable de tramitar la queja y está compuesta por tres personalidades independientes, quienes presentan sus recomendaciones al final del proceso. Bajo este mecanismo se llegó a aplicar el artículo 33 de la Constitución de la OIT en el caso Myanmar, en el que se otorga potestad a la conferencia para adoptar las medidas que estime conveniente para obtener el cumplimiento de dichas recomendaciones. Este caso ha sido importante para la OIT en diversos aspectos. En primer lugar, exige el respeto de los derechos fundamentales en el trabajo, en este caso la prohibición del trabajo forzoso. En segundo lugar, por primera vez se hace uso del artículo 33 de la Constitución de la OIT como mecanismo de control, lo que evidencia que el organismo internacional cuenta con las potestades constitucionales suficientes para enfrentar graves violaciones de derechos. En tercer lugar, el debate interno durante la elaboración de la Declaración de la OIT (1998) ha provocado una atmósfera institucional en favor del respeto irrestricto de los derechos.

Existen dos procedimientos especiales de control: incumplimiento de someter los convenios y recomendaciones a las autoridades competentes, y quejas por violación de derechos sindicales. El primero ha resultado ineficaz porque los Estados, titulares para iniciar el procedimiento, no lo han empleado. En cambio, las quejas sindicales han representado uno

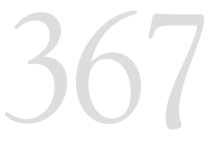

LOS DERECHOS HUMANOS

LABORALES EN

EL DERECHO

INTERNACIONAL 
de los procedimientos más dinámicos de protección dentro de la OIT. Estas son presentadas por organizaciones nacionales e internacionales, así como por gobiernos nacionales contra un Estado que haya violado la libertad sindical. Este procedimiento se aplica inclusive para los Estados que no han ratificado ninguno de los convenios internacionales de libertad sindical. El Comité de Libertad Sindical y la Comisión de Conciliación en Materia de Libertad Sindical son los órganos responsables de las quejas, aunque el comité ha sido el verdadero órgano de protección.

El sistema de solución de diferencias de la Organización Mundial del Comercio (en adelante, $\mathrm{OMC}$ ) se ha visto abocado a resolver casos en los que la materia laboral estaba presente, a pesar de que el propio organismo internacional pretendía excluirlo dentro de sus labores institucionales. En la práctica, resulta difícil establecer una división entre el proceso productivo - del cual el trabajo forma parte- y el intercambio de mercancías en el mercado internacional, cuando entre ambos existe una estrecha interrelación.

El primer caso importante fue Massachussets-Myanmar; en este, se ventila si las prohibiciones en la compra de bienes o la contratación de servicios contra las personas o las empresas que realicen transacciones mercantiles con el régimen militar birmano son violatorias del Acuerdo sobre Contratación Pública (ACP). El fundamento de la acción es presionar al gobierno militar por su política represora que viola los derechos humanos en el país. El caso se resuelve antes de un pronunciamiento del órgano de control porque Estados Unidos retira la medida estatal. Lo sustancial del caso reside en que una medida coercitiva de protección de los derechos humanos laborales podría ser evaluada ante la OMC.

El caso Amianto consiste en la prohibición de Francia - y se extiende a la Unión Europea - del ingreso de amianto a su mercado por tratarse de un producto cancerígeno que atenta contra la salud de los trabajadores y de la población en general. El órgano de apelación resuelve que Francia puede adoptar medidas de restricción para la protección de su población, en tanto esas restricciones no estén en contradicción con la normativa de la OMC. Para el sistema de solución de diferencias no se consideran las normas convencionales provenientes de otros instrumentos internacionales, aunque los Estados los hayan ratificado. Bajo dicha interpretación, una medida de protección que no es conforme a los acuerdos de la OMC sería declarada incompatible. No obstante, el caso representa un importante antecedente para los derechos humanos laborales dentro de la OMC. Así, las medidas dirigidas a proteger la seguridad y la salud de los trabajadores no se consideran incompatibles con sus normas.

En el caso SGP, se discute si el Sistema de Preferencias Arancelarias de la Unión Europea respeta la normativa de no discriminación de la OMC. El caso resulta relevante en tres aspectos. Primero, aborda la naturaleza 
de los sistemas de preferencias arancelarias en el marco de la OMC, especialmente cuando se ponen en tela de juicio las políticas comerciales que favorecen a determinados países en desarrollo y excluyen a otros. Después, marca un valioso antecedente ante una eventual disputa dentro del sistema de solución de diferencias de la OMC sobre una política comercial que promueva la protección de los derechos humanos - y, dentro de ellos, los laborales-. Finalmente, evidencia las dificultades de implementar cláusulas sociales —que, a diferencia de las preferencias arancelarias, son sancionadoras- dentro del marco de la OMC. El órgano de apelación resuelve que un Sistema Generalizado de Preferencias (en adelante, SGP) debe estar abierto a todos los países en desarrollo sin establecer ningún tipo de distingo o discriminación entre ellos. A su vez, dentro del SGP se pueden establecer subcategorías diferentes de beneficiarios en función de necesidades de desarrollo, financieras o comerciales, siempre que existan mecanismos claros que evidencien que cualquier país en desarrollo sujeto a dicha situación se puede beneficiar de ellos. También permite que un SGP considere la protección de los derechos humanos como un criterio para una subcategoría diferente de beneficiarios, siempre que respete el marco normativo de la OMC. Por último, sería difícil implementar cláusulas sociales con carácter sancionador dentro del actual marco normativo de la OMC.

La multitud de procedimientos de control en los distintos sistemas de derechos humanos, la variedad de órganos de control especializados, la protección del listado de derechos humanos laborales y los pronunciamientos o comentarios sobre ellos eliminan cualquier duda sobre el carácter justiciable de los derechos humanos laborales.

V.

Las normas de jus cogens son normas imperativas e inderogables del Derecho internacional general, aceptadas y reconocidas por la comunidad internacional en su conjunto. Estas son identificadas por la jurisprudencia internacional y por la práctica de los Estados. Apoyándose en la jurisprudencia de los tribunales internacionales y en los comentarios de la Comisión de Derecho Internacional, se puede establecer un listado de normas de jus cogens: la prohibición del genocidio, el principio de inviolabilidad de los diplomáticos y de sus locales, la prohibición de los actos de agresión, uso o amenaza de la fuerza, la prohibición de la esclavitud, el principio de igualdad de las personas ante la ley, la prohibición de la discriminación, la privación abusiva de la libertad, la prohibición de la tortura, el derecho a la autodeterminación de los pueblos, y los principios del Derecho internacional humanitario.

En cambio, las obligaciones erga omnes son aquellas conductas exigibles al Estado en relación con la comunidad internacional en su conjunto. 
Así, todas las normas imperativas imponen obligaciones erga omnes, pero no necesariamente todas las obligaciones erga omnes provienen de una norma imperativa. Finalmente, aquellos derechos recogidos en las normas de jus cogens, sin incluir los principios ordenadores del Derecho internacional, componen el núcleo duro de los derechos humanos. Al utilizarse como sinónimos, especialmente entre las normas imperativas y el núcleo duro, se puede caer en serias contradicciones.

La polémica con el núcleo duro de los derechos humanos reside en que la doctrina no suele ser uniforme en la identificación de los derechos que son recogidos por las normas imperativas. La disparidad de listados le resta solidez jurídica al término, especialmente cuando las normas imperativas se identifican mecánicamente con el núcleo duro. En ese «salto» mecánico, se pierde el criterio de que la práctica de los Estados y la jurisprudencia internacional son los encargados de dar contenido material a las normas de jus cogens. Cuando los autores definen los rasgos que identifican un derecho humano dentro del núcleo duro, curiosamente recurren a los mismos argumentos ya superados que dividían los derechos humanos en derechos civiles y derechos sociales, y que preferían a los primeros. Se trataría, en mi opinión, de la reposición de la polémica bajo otros «ropajes» jurídicos, pero en esta ocasión dentro de la propia categoría de los derechos humanos. La diferencia valorativa ya no reside en pertenecer a los derechos civiles, sino en ubicarse dentro del núcleo duro de los derechos humanos.

Se suele señalar que el núcleo duro de los derechos humanos puede ser identificado en las normas inderogables del Pacto Internacional de Derechos Civiles y Políticos, los Convenios de Ginebra, la Convención Americana sobre Derechos Humanos y el Convenio Europeo para la Protección de los Derechos Humanos y Libertades Fundamentales. Sin embargo, allí también se presentan serias disparidades entre los instrumentos internacionales. A esto se agrega que no sería conveniente considerar como un núcleo duro ni siquiera al mínimo común denominador de los derechos inderogables, pues su cantidad de derechos es inferior a la reconocida internacionalmente dentro de las normas imperativas.

Dentro del ámbito de la doctrina jurídica del Derecho internacional de trabajo también se plantea la existencia de un núcleo duro de derechos laborales. Al igual que en el caso anterior, existe una gran disparidad sobre su identificación, por lo que resulta difícil establecer cuál es el listado de derechos laborales esenciales. Estas propuestas doctrinarias tampoco se apoyan en los instrumentos internacionales; se trata más bien de criterios como la protección satisfactoria de los trabajadores, la práctica internacional de algunos Estados o las formas intolerables de explotación, que sirven como argumentos para definir la inclusión o la exclusión de un derecho laboral dentro del núcleo duro. En mi opinión, mientras no se formule un núcleo duro asentado sobre la propia 
normativa internacional laboral, se debería dejar de lado este tipo de propuestas. La protección del íntegro listado de derechos humanos laborales no puede estar condicionada por fórmulas ajenas al Derecho internacional positivo.

En el caso de la OIT, la formulación de un núcleo duro de derechos se refiere exclusivamente al ámbito de sus normas internacionales del trabajo y no a los instrumentos internacionales de derechos humanos. Es un distingo sustancial porque el organismo internacional define claramente que es dentro de su marco normativo donde se postula el núcleo duro. En su Declaración de 1998, la OIT señala que existen cuatro derechos fundamentales en el trabajo: la libertad de asociación y la libertad sindical y el derecho a la negociación colectiva; la eliminación del trabajo forzoso u obligatorio; la abolición del trabajo infantil; y la eliminación de la discriminación en materia de empleo y ocupación.

El primer argumento para justificarlo reside en que estos derechos recogidos en convenios internacionales fundamentales han recibido una masiva cantidad de ratificaciones por parte de sus Estados miembros. Sin embargo, no se puede considerar como un argumento sólido porque también existen otros convenios internacionales del trabajo que han recibido una significativa cantidad de ratificaciones y no forman parte de los derechos fundamentales en el trabajo. Además, el criterio de la cantidad de ratificaciones de un instrumento internacional no está vinculado necesariamente con la importancia de los derechos.

El segundo argumento sostiene que los derechos fundamentales en el trabajo se encuentran recogidos como principios en la Constitución de la OIT y la Declaración de Filadelfia. Sin embargo, ambos instrumentos internacionales recogen más derechos laborales y no se limitan solo a los cuatro establecidos en la Declaración de la OIT de 1998.

El tercer argumento afirma que los cuatro derechos fundamentales en el trabajo son imprescindibles en cualquier ordenamiento jurídico, o son suficientes para asegurar que se respete la libertad de la autonomía de los trabajadores. En efecto, no cabe un ordenamiento jurídico que respete la dignidad en el trabajo si es que no incluye estos cuatro derechos. Sin embargo, no son suficientes. A modo de ejemplo, resultaría difícil sostener que el derecho a la seguridad y salud en el trabajo — directamente vinculado al derecho a la vida y a la integridad física y moral de la persona - pueda ser excluido dentro de un listado de derechos laborales imprescindibles en cualquier ordenamiento jurídico. Del mismo modo, no se puede asegurar la libertad de la autonomía de los trabajadores si no se presupone que estos pueden actuar libremente sin ningún tipo de impedimento. Mientras no disfruten de un derecho general que garantice sus condiciones de vida en el mundo laboral — por ejemplo, la jornada máxima de trabajo o el derecho a un salario mínimo-, sería difícil sostener que son autónomos para actuar y, lamentablemente, esto

LOS DERECHOS

HUMANOS

LABORALES EN

EL DERECHO

INTERNACIONAL 
no puede ser asegurado solo con los cuatro derechos fundamentales en el trabajo de la OIT.

Con independencia de la debilidad o fortaleza de los argumentos, los derechos fundamentales en el trabajo son la formulación de un núcleo duro institucional de derechos laborales dentro de la OIT. Su objetivo es alcanzar la universalización de los ocho convenios fundamentales con la ratificación de todos sus Estados miembros y asegurar su protección por medio de los procedimientos de control institucional.

Sin embargo, el «núcleo duro» institucional termina ensombreciendo al resto de los derechos humanos laborales no considerados por la Declaración de la OIT. En el plano internacional, se interpreta que los cuatro derechos laborales de la Declaración son aquellos esenciales para cualquier relación laboral, sin considerar el listado de derechos laborales recogidos en los instrumentos internacionales de derechos humanos. Empero, esto se viene matizando desde el propio organismo internacional con su política institucional de alcanzar los cinco objetivos estratégicos dentro de los que se incluyen la política de empleo, la seguridad social y las condiciones de trabajo. En todo caso, es el conjunto de los derechos humanos laborales los que aseguran la dignidad en el trabajo y la satisfacción de las necesidades básicas en el mundo laboral.

En mi opinión, en lugar de formar un «núcleo duro» de derechos humanos laborales, resulta más importante para el Derecho internacional del trabajo resaltar la existencia de un jus cogens laboral. En el listado de normas de jus cogens establecido por la jurisprudencia internacional y la práctica de los Estados, se ubican dos derechos humanos laborales: la prohibición de la esclavitud y la prohibición de la discriminación. El primer caso se puede extender a la prohibición de la servidumbre, en razón de que los instrumentos internacionales de derechos humanos los equiparan y ambos conceptos — esclavitud y servidumbre — tienen una raíz común: la ausencia de libertad en la persona que ejercita el trabajo. Sobre el segundo caso, la Corte Interamericana ha sido clara en afirmar que las diversas causas que provocan la discriminación se encuentran prohibidas por una norma de jus cogens. Así, tanto la prohibición de la esclavitud y de la servidumbre como la prohibición de la discriminación en el ámbito laboral constituyen, en la etapa actual del Derecho internacional, los dos derechos humanos laborales recogidos en normas imperativas o de jus cogens.

Esto no impide que otros derechos humanos laborales sean recogidos posteriormente por normas imperativas del Derecho internacional. La jurisprudencia internacional viene consolidando la equiparación entre la prohibición de la esclavitud con la prohibición del trabajo forzoso dentro de sus interpretaciones sobre la normativa penal internacional. El Tribunal Penal Internacional para la Antigua Yugoslavia, apoyándose en la Comisión de Derecho Internacional, sostiene que las 
formas contemporáneas de la esclavitud forman parte del enslavement. En el mismo sentido se pronuncia el Tribunal Especial Independiente para Sierra Leona. Sin embargo, no existe todavía un pronunciamiento judicial internacional en el que se afirme que la prohibición del trabajo forzoso se encuentra recogida en una norma de jus cogens.

Lo sustancial es que no existiría controversia en reconocer que la prohibición de la esclavitud y de la servidumbre y la prohibición de la discriminación en el ámbito laboral constituyen los dos derechos humanos laborales recogidos por normas imperativas del Derecho internacional general.

La importancia del jus cogens laboral reside en que cualquier tratado internacional o acto unilateral de los Estados sería nulo si estuviera en conflicto con los derechos humanos laborales recogidos en las normas imperativas del Derecho internacional general. Así, el jus cogens laboral gozaría de un carácter imperativo tanto ante el ordenamiento internacional como ante los nacionales. 